\section{Dr Keith Hawton}

Dr Keith Hawton was recently presented with the Erwin Stengal Research Award at the biannual meeting of the International Association of Suicide Prevention. This is an international award, given every two years for research contributions in the field of suicidal behaviour, which Dr Hawton is the first Briton ever to receive.

\section{Work \& Training-The Future For Mental Health Care Stafi}

The Sainsbury Centre for Mental Health is to carry out a national review of the roles and training of mental health care staff. The review, conducted by a working party chaired by Rabbi Julia Neuberger, Chair of Camden $\&$ Islington Community Health Services NHS Trust, was launched on Monday 12 June 1995 at the QEII Centre, London SWl. Further information: Sue Spenceley, The Sainsbury Centre for Mental Health, 134-138 Borough High Street, London SEl ILB, Tel: 0171-403 8790 .

\section{Refugee council creates first mental health directory for refugees}

The Refugee Council has created a directory to identify the mental health services available to refugees in the Greater London area. It is intended to help refugees and their advisers get information about specialised agencies that may be able to offer appropriate services, and provide useful guidelines for those who are developing more accessible services for refugees.

The Mental Health Directory is partly funded by the Mental Health Foundation who feel refugee mental health projects are often isolated and poorly funded, and it is hoped that the directory will help to make links between refugees, projects, and the main mental health care agencies. For information contact Susannah Cox/Halley Cohen, Press Office, on 0171-820 3045/3044, or Antionette Dale-Roberts, Mental Health Foundation on 0171-580 0145 .

\section{New Publications}

New titles now available from Gaskell/The Royal College of Psychiatrists include Seminars in Clinical Psychopharmacology edited by David J. King and Mental Health Care in China by Veronica Pearson. Priced at $£ 20$ and $£ 12.50$, respectively, these may be purchased from the College by mail order (0171-235 2351) or from the BMJ bookshop located at Burton Street, London WC11 9JR. which currently stocks all Gaskell titles.

Alzheimer's Challenged and Conquered? by Louis Blank will be available from 30 October, at £14.95, from Foulsham Publishers at Bennetts Close, Sippenham SLl 5AP (tel: 01753-526769).

Getting the Best from your Counsellor or Psychotherapist is available priced $£ 1.00$ plus a 29p A5 SAE from MIND Publications, 15-19 Broadway, Stratford E15 4BQ.

Joint Statement on Psychological Therapies for Adults in the NHS has been published by The British Psychological Society and The Royal College of Psychiatrists. Further information: Sue Cavill, The British Psychological Society (tel: 01162529500 ) or Deborah Hart, The Royal College of Psychiatrists (tel: 0171-235 2351).

In Control of Panic \& Anxiety is a new audio tape available for sufferers, from Feel Good, PO Box 2, Stockport SK4 2DT. 